\title{
A comunidade terapêutica para recuperação da dependência do álcool e outras drogas no Brasil: mão ou contramão da reforma psiquiátrica?
}

\author{
The therapeutic community for recuperation from addiction \\ to alcohol and other drugs in Brasil: in line with \\ or running counter to psychiatric reform?
}

Pablo Andrés Kurlander Perrone ${ }^{1}$

${ }^{1}$ Faculdade de Medicina de Botucatu, UNESP. R. Bento Lopes s/n, Distrito de Rubião Jr. 18.618-970 Botucatu SP Brasil. pablok@novajornada.org.br
Abstract In the second half of the last century a revolutionary movement began in the world mental health scenario, namely Psychiatric Reform. At the same juncture, the concept was also put forward for Therapeutic Communities, which would later become the tried and tested model for treatment of addiction to alcohol and other drugs. However, due to the alarming increase of this problem in Brazil, as well as the absence of public policies to address the problem, there was an indiscriminate proliferation of chemical dependency internment locations that, despite calling themselves Therapeutic Communities, in no way resembled the initial model proposed. These places featured inhuman and iatrogenic practices, very similar to those criticized by the Psychiatric Reform movement, which consequently discredited the Therapeutic Community model. This article seeks to demonstrate, through bibliographic research, how the conceptual and methodological bases of Psychiatric Reform closely resemble the Therapeutic Communities movement, having appeared at the same time and for the same reason, and how the lack of control and regulation of chemical dependency internment locations in Brazil has contributed to the current disrepute of this model.

Key words Therapeutic Community, addiction to alcohol and other drugs, Psychiatric Reform
Resumo Na segunda metade do século passado iniciava-se um movimento revolucionário no cenário mundial da saúde mental: a Reforma Psiquiátrica. No mesmo momento nascia a proposta das Comunidades Terapêuticas, que mais tarde se tornaria um modelo consagrado de atendimento para a dependência do álcool e outras drogas. Por outro lado, com o alarmante crescimento deste problema no Brasil, assim como pela ausência de políticas públicas que dessem conta do problema, houve uma indiscriminada proliferação de locais de internação para dependentes químicos que, mesmo se autodenominando como Comunidades Terapêuticas, em nada se assemelham ao modelo inicial proposto. Estes locais apresentam práticas desumanas e iatrogênicas, muito semelhantes às criticadas pelo movimento da Reforma Psiquiátrica, o que tem provocado o descrédito para com o modelo das Comunidades Terapêuticas. Este artigo tem como objetivo demonstrar, através de pesquisa bibliográfica, como as bases conceituais e metodológicas da Reforma Psiquiátrica se assemelham profundamente as do movimento das Comunidades Terapêuticas, tendo surgido na mesma época e pelo mesmo motivo, e como a falta de regulamentação dos locais de internação para dependentes químicos no Brasil tem contribuido com o atual descrédito deste modelo.

Palavras-chave Comunidade terapêutica, Dependência do álcool e outras drogas, Reforma psiquiátrica 


\section{Introdução}

Desde o próprio nascimento da psiquiatria, esta tem tentado se reformar constante e incansavelmente, como afirmam Tenório ${ }^{1}$ e Sampaio et al. ${ }^{2}$, talvez por compreender as suas limitações e contradições desde o seu momento primigênio.

Teriam sido os próprios reformadores da Revolução Francesa que teriam delegado a Pinel a tarefa de "humanizar e dar um sentido terapêutico aos hospitais gerais, onde os loucos encontravam-se recolhidos juntos com outros marginalizados da sociedade" .

Teria sido a meados do século XX, após a $2^{\mathrm{a}}$ Guerra Mundial, como afirmam Amarante e $^{3}$ Jorge $^{4}$, que Maxwell Jones ${ }^{5}$ inicia o movimento definitivo de reforma da psiquiatria mundial, desenvolvendo o modelo de Comunidade Terapêutica $(\mathrm{CT})$ psiquiátrica.

Maxwell Jones ${ }^{5}$ visava uma maior interação do paciente no seu próprio processo, fazendo-se este assim partícipe das suas pequenas conquistas cotidianas. Ele afirma que "de maneira recíproca, a total dependência e passividade [...] precisa ser mudada a fim de permitir-lhe uma participação mais ativa em sua própria cura e na dos outros".

Juntamente com Jones, muito relevante foi a antipsiquiatria de Franco Basaglia, movimento que denunciava os valores tradicionais da psiquiatria, que tratava o louco como um ser alienado, à parte da sociedade, afirmando que "a psiquiatria sempre colocou o homem entre parênteses e se preocupou com a doença"'.

Na década de ' 80 chegaria ao Brasil este movimento, como afirmam Tenório ${ }^{1}$, Lüchmann e Rodrigues $^{6}$ e Pitta ${ }^{7}$ sob a égide de "luta antimanicomial", que teria como foco principal a retomada da cidadania do doente mental, como forma de melhorar o seu grau de autonomia, e com este a sua qualidade de vida.

Até o momento, a clínica era o principal dispositivo construído socialmente para se relacionar com a loucura, como afirmam Tenório ${ }^{1}, \mathrm{Mari}^{8}$ e Costa et al. ${ }^{9}$, e a luta antimanicomial representaria justamente a superação deste paradigma.

Por outro lado, existiam os antecedentes de Jones e Basaglia, acima descritos, com as propostas de Psiquiatria Comunitária e o movimento das CT Psiquiátricas, que visavam abordar o tema da doença mental desde uma perspectiva humanizada e, certamente, não predominantemente clínica.

Este movimento das CT Psiquiátricas, original de Maxwell Jones, teria se desdobrado, a par- tir da década de 60, no trabalho de recuperação de dependentes do álcool e outras drogas, tendose tornado atualmente uma das modalidades mais procuradas, tanto no Brasil como em muitas partes do mundo, em detrimento dos antes tradicionais tratamentos de base medicamentosa hospitalar, como afirmam De Leon ${ }^{10}$ e Fracasso ${ }^{11}$.

Isto se deve também ao fato de que o alcoolismo e, principalmente, a dependência de drogas, mesmo havendo registro do consumo de ambas desde a antiguidade ${ }^{10-12}$, são doenças emergenciais da atualidade, pelo que as CT têm proliferado de forma abundante e desregulada no Brasil, nos últimos 20 anos.

Por este motivo, a proposta das CT no Brasil foi discutida pelo Ministério da Saúde ${ }^{13}$ em sua "Política para a atenção integral a usuários de álcool e outras drogas", e regulamentada pela Agência Nacional de Vigilância Sanitária (Anvisa) $)^{14}$, em sua RDC 101/2001, dando forma e conteúdo oficial a um movimento de repercussão mundial que oferecia um modelo diferenciado de tratamento.

Contudo, o movimento das CT no Brasil tem sofrido severas críticas ao longo da última déca$\mathrm{da}$, assim como muitas denúncias e rigorosas fiscalizações, como a realizada em 2011 pelo Conselho Federal de Psicologia (CFP) ${ }^{15}$, que se deparou com inúmeras e imperdoáveis práticas desumanas e iatrogênicas, que em muito se assemelhavam às práticas dos primeiros Hospitais Psiquiátricos, combatidos pelo movimento primitivo da Reforma Psiquiátrica, assim como pelo Movimento de Luta Antimanicomial no Brasil.

Por estes motivos, o presente artigo busca analisar, de acordo com a história e as bases epistemológicas da Reforma Psiquiátrica e do surgimento das CT, assim como a sua articulação e funcionamento na atualidade, se, de fato, o trabalho das CT no Brasil se orienta em prol da Reforma Psiquiátrica e do Movimento de Luta Antimanicomial, ou se, pelo contrário, pode ser considerada uma forma de regressão aos padrões primitivos de tratamento das doenças mentais.

\section{Metodologia}

Foi realizada, com a finalidade de embasar teoricamente o debate proposto, uma revisão bibliográfica em livros especializados, artigos científicos nacionais e internacionais pesquisados em bases de dados (SciELO, Lilacs, Portal Capes), documentos oficiais e sites institucionais, sem um recorte temporal específico. 


\section{As bases conceituais e metodológicas da reforma psiquiátrica no Brasil}

Segundo Tenório ${ }^{1}$ "o movimento que denominamos reforma psiquiátrica brasileira data de pouco mais de vinte anos e tem como marca distintiva e fundamental o reclame da cidadania do louco".

No Brasil, este movimento de quebra de paradigmas fundamentais da psiquiatria deu à luz o Movimento de Luta Antimanicomial, como afirmam Lüchmann e Rodrigues ${ }^{6}$, criado a partir do II Congresso Nacional do Movimento dos Trabalhadores em Saúde Mental (MTSM), ocorrido em Bauru, SP, em 1987, onde foi redigido o Manifesto de Bauru, que seria considerado o seu documento de fundação.

As bases deste movimento são claras e concisas, porém muito complexas em sua prática, principalmente face à hegemonia dos modelos hospitalocêntricos tradicionais incrustados na cultura e no imaginário popular. "Não se trata de aperfeiçoar as estruturas tradicionais [...], mas de inventar novos dispositivos e novas tecnologias de cuidado"1.

Para Lobosque 6 "o Movimento de Luta Antimanicomial é um movimento social, plural, independente, autônomo que deve manter parcerias com outros movimentos sociais [...] para que a sociedade se aproprie desta luta".

Segundo Vecchia e Martins ${ }^{16}$ os conceitos basais deste movimento implicam "a defesa tanto da desospitalização da população cronificada, mantida em longa permanência, quanto um processo de desinstitucionalização", o que confirma as ideias de Lüchmann e Rodrigues ${ }^{6}$, conforme os quais "a ruptura com o modelo manicomial significa [...] muito mais do que o fim do hospital psiquiátrico, pois toma como ponto de partida [...] a crítica profunda aos olhares e concepções deste fenômeno".

Desospitalização seria, basicamente, o atendimento ao doente fora do ambiente hospitalar. Segundo Costa-Rosa et al. ${ }^{17}$, é muito importante, neste caso, "a substituição do modelo hospitalocêntrico por uma rede de serviços diversificada e qualificada [...] através de programas públicos de lares e pensões protegidas".

$A$ ideia de redes vai além de uma dimensão estratégica, caracterizada, entre outros, pela capacidade de articulação, organização e mobilização, na medida em que comporta, de forma nuclear, uma noção de solidariedade pautada no compartilhamento de princípios e valores ${ }^{6}$.

Já a Desinstitucionalização é um conceito mais abrangente, que segundo Saraceno et al. ${ }^{18}$ "con- siste em trabalhar para eliminar a realidade e a cultura institucional [...] e suas consequências: violência, miséria, isolamento, falta de dignidade, injustiça e ampliação da enfermidade institucional, seja dos pacientes, seja dos que cuidam deles".

Cabe lembrar, como consta nas políticas públicas $^{13-19}$, que em ambos os casos não se desconsideram absolutamente os atendimentos com internação, desde que sejam de curta duração (até 90 dias), e sempre com o intuito final da alta, com o subsequente acompanhamento posterior.

Esta crítica leva, em primeiro lugar, à superação do paradigma da clínica, como nomeia Tenório $^{1}$, o que representa uma forma embrionária de independência do modelo médico, segundo o qual se trata a doença, e não o doente.

Esta nova percepção levaria a uma notória "ampliação do conceito de saúde, incluindo em seus determinantes as condições gerais de vida" ${ }^{17}$, incluindo assim a melhora da qualidade de vida como um dos principais objetivos a serem atingidos através dos dispositivos terapêuticos utilizados, e não mais somente a retirada ou a diminuição dos sintomas mais evidentes.

Outra modificação substancial no conceito de saúde mental seria o novo modelo psicossocial de atendimento, citado por Costa-Rosa et al. ${ }^{17}$, segundo o qual "o engajamento subjetivo e sociocultural são indissociáveis da definição de saúde mental". Este modelo psicossocial seria o contraponto do já ultrapassado modelo asilar, e significaria uma superação do modo de relação sujeito-objeto característico do modelo médico.

A horizontalização das relações interprofissionais, assim como as intrainstitucionais, incluindo as paciente-equipe de saúde, seria uma das premissas básicas deste novo modelo, segundo Costa-Rosa et al. ${ }^{17}$, e que suporia uma forma de controle social compartido, através do qual o paciente e os familiares teriam prerrogativas semelhantes e equivalentes às da equipe de saúde para poder gerir cada fase do tratamento.

O que está em jogo, portanto, é a reapropriação do sujeito; do sentido e da motivação humana; reapropriação da capacidade de forjar sua própria identidade, capacidade esta historicamente amputada pelos processos de manipulação e controle dos aparatos de gestão dos sistemas complexos ${ }^{6}$.

Desta forma, estes autores focam a atenção na reapropriação da identidade como mecanismo altamente benéfico na relação de saúde que se propõe estabelecer neste novo modelo de atenção. O doente mental não somente teria sua saúde física restaurada ou melhorada, mas poderia 
ter acesso a práticas que o levassem de volta a si mesmo, de encontro com a sua história, com a sua singularidade.

Assim surge o conceito de singularização no atendimento ao doente mental, que seria, segundo Tenório ${ }^{1}$, uma forma de tratá-lo de acordo com as suas características e necessidades pessoais, fugindo da lógica asilar capitalista de massificação.

Para ser almejada e alcançada, a singularização dependerá de que a forma das relações sociais e humanas na instituição parta da horizontalização como meta e, em alguma medida, seja vivida como exercício ${ }^{17}$.

Considerando todo o apresentado até o momento, fica evidente que o novo modelo proposto visa como finalidade última a ressocialização, ou seja, o retorno do doente mental à sociedade e à família, de acordo com as reais possibilidades de cada caso, e para isto busca desenvolver diversos dispositivos que se adaptem a cada necessidade, como o CAPS, residências terapêuticas, hospitais-dia, NASF, consultórios de rua e outros dispositivos que podem ser adaptados com a finalidade de garantir a integralidade do atendimento ao doente mental desospitalizado ${ }^{1,2,7-9,16,17,19}$.

A necessidade do retorno à sociedade, como prática despatologizante, se torna um dos estandartes do Movimento de Luta Antimanicomial no Brasil, assim como da Reforma Psiquiátrica no mundo. Para isto é imprescindível garantir ao indivíduo o cuidado nesta tarefa de readaptação social, e por este motivo o cuidado, em saúde mental, amplia-se no sentido de ser também uma sustentação cotidiana da lida diária do paciente, inclusive em suas relações sociais ${ }^{1}$.

Desta forma, segundo Vecchia e Martins ${ }^{16}$ : o trabalho de desconstrução do manicômio e da cultura manicomial envolve politicas sociais de conjunto, implicando o reconhecimento da necessidade de: moradias substitutivas e assistidas para exinternos psiquiátricos; espaços de trabalho protegido (mas não 'tutelado'); inserção em atividades culturais e de lazer etc...

Outra característica indiscutível do modelo de atenção proposto pelo Movimento de Luta Antimanicomial é a maciça participação dos familiares dos usuários, tanto na discussão política das diretrizes e normativas vigentes, quanto no cotidiano do atendimento, como agentes de saúde do mais alto escalão, tendo participado do movimento desde o seu nascimento, como afirmam diversos autores ${ }^{1,7-9,16,17}$.

Nunca é demais, portanto, insistir que é a rede - de profissionais, de familiares, de organizações governamentais e não governamentais em intera- ção constante, cada um com seu núcleo específico de ação, mas apoiando-se mutuamente, alimentando-se enquanto rede - que cria acessos variados, acolhe, encaminha, previne, trata, reconstrói existências, cria efetivas alternativas de combate ${ }^{13}$.

Como se confirma através destes conceitos, a Reforma Psiquiátrica e o Movimento de Luta Antimanicomial são movimentos que visam muito mais do que apenas a desaparição dos manicômios. Eles buscam, acima de tudo, a qualidade de vida do doente mental, a atenção integral, a humanização do atendimento, através de um novo olhar que se faz cada vez mais urgente numa sociedade que pretenda dizer-se justa e democrática.

\section{A comunidade terapêutica para recuperação da dependência do álcool e de outras drogas: modelo e método}

Quem teve a oportunidade de aproximar-se de uma CT, tem a sensação de haver participado de 'algo diferente'. Quem teve, além disso, a oportunidade de conviver durante algum tempo numa CT terá uma lembrança que o acompanhará pelo restante dos seus dias ${ }^{12}$.

Como foi visto acima, as CT existem há mais de 60 anos, tendo-se consagrado nas duas últimas décadas como um dos modelos mais procurados para a recuperação da dependência do álcool e outras drogas, tanto no Brasil como em muitas partes do mundo, por oferecerem uma inovadora forma de tratar o problema, tão implacável e urgente, independentemente da cultura e do nível de desenvolvimento das populações atingidas.

Neste momento serão apresentadas apenas as bases metodológicas e conceituais deste modelo, comparando-as com as recém-explicadas, referentes à Reforma Psiquiátrica e ao Movimento de Luta Antimanicomial, deixando as críticas ao respeito da aplicação das mesmas no Brasil para outro tópico adiante.

Segundo consta na RDC no $101^{14}$ (atual RDC $n^{\circ} 29$, de 30/06/11 ${ }^{20}$ ) da Agência Nacional de Vigilância Sanitária (Anvisa) as CT: "são serviços urbanos ou rurais, de atenção a pessoas com transtornos decorrentes do uso ou abuso de substâncias psicoativas (SPA), em regime de residência ou outros vínculos de um ou dois turnos, segundo modelo psicossocial. São unidades que têm por função a oferta de um ambiente protegido, técnica e eticamente orientado, que forneça suporte e tratamento aos usuários abusivos e/ou dependentes de substâncias psicoativas, durante 
período estabelecido de acordo com programa terapêutico adaptado às necessidades de cada caso. É um lugar cujo principal instrumento terapêutico é a convivência entre os pares. Oferece uma rede de ajuda no processo de recuperação das pessoas, resgatando a cidadania, buscando encontrar novas possibilidades de reabilitação física e psicológica, e de reinserção social”.

O modelo básico de CT é o residencial, como afirmam NIDA $^{21}$, De Leon ${ }^{10}$ e Goti ${ }^{12}$. Existem também CT que trabalham no regime ambulatorial (hospital-dia), outras em regime de internação de curta duração, e outras de longa duração.

De Leon ${ }^{6}$ cita que a permanência tradicional na CT era de 12 a 18 meses, fato que tem se modificado na atualidade, sendo que para as CT filiadas na Federação Brasileira de Comunidades Terapêuticas (FEBRACT) ${ }^{22}$ a permanência padrão varia entre 6 e 9 meses.

De acordo com vários autores ${ }^{10,11,21,23,24}$, um dos critérios mais determinantes do trabalho da CT atual é o público atendido, sendo o foco o atendimento exclusivo de dependentes do álcool e de outras drogas.

Em relação ao sexo da população atendida, as CT podem ser masculinas, femininas ou mistas, prevalecendo, no Brasil, as CT masculinas, como pode se perceber pela amostra referente às CT filiadas na FEBRACT ${ }^{22}$ assim como pelo Relatório do $\mathrm{CFP}^{15}$. O critério de idade também é muito variável, mas o padrão no Brasil é entre 18 e 65 anos, havendo algumas CT que admitem menores de idade, e outras que aceitam idosos para o tratamento.

Já em relação à quantidade de residentes atendidos numa CT, esta é muito variável. Segundo dados do NIDA $^{21}$ um programa típico de CT abrigaria entre 40 e 80 pessoas.

Para Maxwell Jones ${ }^{5}$ a ideia primeva da CT seria o ambiente democrático, de mobilidade social, no qual todos os membros possam fazer-se responsáveis pelo grupo e pela instituição, independentemente das suas características pessoais.

Desta forma nas CT democráticas a autoridade seria uma prerrogativa do grupo como um todo, e não de um ou alguns membros do mesmo. Isto implica uma grande complexidade do espectro social da CT, normalmente muito difícil de administrar e regular. Como mostra De Leon ${ }^{10}$, para todos os efeitos, existe uma autoridade máxima de referência dentro do ambiente da CT, sem que por isso desapareça o ambiente democrático de relações horizontais e de controle social compartido.

Como mostra a regulamentação da Anvi$\mathrm{sa}^{14,20}$, as CT baseiam seus programas de trata- mento no modelo psicossocial, considerando sempre as relações interpessoais como o principal agente de modificações de comportamento, como afirma De Leon ${ }^{10}$.

Maxwell Jones ${ }^{5}$ afirma que quaisquer habilidades, tanto dos terapeutas quanto da instituição como um todo, seriam ineficazes se o clima social da CT como unidade estiver em contradição com as mesmas.

Por este motivo, Emilio Rodrigué ${ }^{25}$ afirma que:

Sabe-se que uma CT é, para usar um quase neologismo antiantiterapêutica. Ou seja, soluciona determinados agentes antiterapêuticos, patógenos, tais como a privação sensorial e social, próprios das instituições totais em geral, e do asilo clássico em particular. [...] Para diminuir a privação emocional e social a CT deve proporcionar uma série de papeis sociais.

Para Maria Elena Goti ${ }^{12}$ a CT é:

uma instituição onde tem lugar um processo de crescimento pessoal acompanhado de um processo de aprendizagem social. Isto implica que não é um lugar onde alguém se 'cura', mas onde muda, cresce e amadurece, e onde aprende a ser um membro útil e produtivo para a sociedade.

Um dos principais avanços das CT contemporâneas, para De Leon ${ }^{10}$, é “a passagem [...] de uma comunidade alternativa para dependentes químicos excluídos que presumivelmente não tinham condições de viver em sociedade a uma instituição de serviços de atenção [...] que prepara os indivíduos para a reintegração à sociedade mais ampla".

Ele ainda afirma que "é ao se esforçar para satisfazer as expectativas de participação da comunidade que os residentes perseguem suas metas individuais de socialização e crescimento psicológico". Desta forma, o dependente que consegue socializar-se dentro da CT teria desenvolvido recursos internos suficientes como para dar conta de uma posterior socialização, no suposto "mundo real".

Não é raro, por este motivo, que algumas CT desenvolvam atividades em conjunto com a comunidade local, atividades estas que, muito além de serem apenas simples ocupações, se tornam dispositivos capazes de fazer com que o paciente se sinta pertencente também ao mundo do lado de fora da CT, estruturando assim a rede de ajuda citada acima pela Anvisa.

Para Badaracco ${ }^{26}$ a recuperação verdadeira passa, inevitavelmente, pela aceitação da realidade, com uma consequente adaptação à sociedade, com seus papéis estabelecidos. Araújo ${ }^{27}$ também 
considera que a verdadeira ressocialização passa pela incorporação de princípios comportamentais e sociais, tais como o entendimento do papel social, assim como por uma integração social pautada pela cooperação e comprometimento.

Por adaptação não se deve entender condicionamento nem abdicação da individualidade, mas sim capacidade de pertencer funcionalmente a um grupo com regras e limites específicos, algo que exige um grau mínimo de capacidade de autocontrole e habilidades sociais básicas.

Como os dependentes apresentam, geralmente, baixos índices de habilidades sociais, dentre elas o autocontrole, o que dificulta muito o seu desenvolvimento familiar, laboral e social, como afirmam Aliane et al..$^{28}$, desenvolver estas habilidades deve fazer parte do processo de recuperação, a fim de garantir o sucesso de uma posterior ressocialização.

Para o NIDA ${ }^{21}$ a recuperação envolve "re-habilitação", o que seria restabelecer o funcionamento das habilidades e valores saudáveis, assim como resgatar a saúde física e emocional. Em outras palavras, retomar um estilo de vida saudável, habilitar novamente aquilo que tinha sido desabilitado por causa da doença.

Por outro lado, quando se fala da recuperação da dependência do álcool e outras drogas não tem como se deixar de pensar na díade doença-pessoa, já que, como afirma De Leon ${ }^{10}$ : "não é a droga, mas a pessoa inteira, o problema a ser tratado". E a pessoa inteira sugere, inevitavelmente, todo o universo psicológico e emocional do dependente.

Assim, desde a perspectiva da CT de De Leon $^{10}$, o que deve ser tratado é a pessoa como ser social e psicológico, ou seja, deve ser tratado o modo como o dependente se comporta, pensa, sente, administra suas emoções e frustrações, suas culpas e tristezas, a sua comunicação com o mundo externo e o interno.

De certa forma, como afirmam Sabino e Cazenave ${ }^{29}$, o dependente é alguém que se encontra diante de uma realidade objetiva e/ou subjetiva insuportável, e que não conseguindo suportar, modificar ou se esquivar desta realidade, lhe resta modificar a percepção que tem da mesma, o que acontece pelo uso do álcool e outras drogas.

Quanto à orientação ética das CT, a instituição regulamentadora brasileira nestas questões é, mais uma vez, a FEBRACT ${ }^{23}$, que constituiu em 1995 o primeiro Código de Ética para as CT, cujos Princípios Fundamentais são:

a) o trabalho nas CT deve ser baseado no respeito à dignidade da pessoa humana; b) a permanência na CT deve ser voluntária e decidida após o candidato ser informado sobre a orientação e as normas em vigor;

c) deve ser assegurado um ambiente livre de drogas, sexo e violência.

Em relação ao acompanhamento familiar, é bastante comum que "a família apresente uma certa resistência, quando solicitada a participar, ou então aceite o tratamento apenas por causa do adicto, do doente, como se ela não precisasse refletir sobre a qualidade da relação familiar" ${ }^{\text {"30. }}$.

Por este motivo a abordagem da CT deve prever a orientação familiar, ou o atendimento psicoterápico propriamente dito, para os casos mais resistentes. Em muitas ocasiões, quando a CT não possui este serviço, as famílias são encaminhadas para Grupos de Apoio para familiares de dependentes do álcool e outras drogas, como o Nar-Anon, Al-Anon ou o Amor Exigente.

Desta forma percebe-se que a modalidade de tratamento da CT abrange um espectro de totalidade, no qual são contemplados os fenômenos individuais e sociais, físicos e psicológicos, caracterizando uma das bases da atenção integral, proposta também pelo modelo da Reforma Psiquiátrica e do Movimento de Luta Antimanicomial no Brasil.

A seguir serão comparados ambos os modelos, com a finalidade de evidenciar as semelhanças existentes, pelo menos no que diz respeito aos seus fundamentos teóricos e metodológicos.

\section{Aproximações e distanciamentos entre os modelos descritos (Reforma Psiquiátrica - Movimento de Luta Antimanicomial - Comunidade Terapêutica)}

A seguir serão apresentados os Quadros 1 e 2: um com as semelhanças entre os modelos acima descritos, e outro com as diferenças entre os mesmos. Ao longo do texto anterior podem-se encontrar - grifados em itálico, para uma melhor visualização - os próximos "conceitos básicos".

Como pode ser visto nestes dois quadros comparativos, as aproximações entre as bases metodológicas e conceituais da Reforma Psiquiátrica e o Movimento de Luta Antimanicomial, com os das CT, são muito maiores do que as suas diferenças.

De acordo com os conceitos apresentados anteriormente, podem ser enumeradas, seguindo estes quadros, onze semelhanças e apenas duas divergências, sendo que estas últimas não seriam absolutas, já que tanto o conceito de $D e$ sospitalização quanto o de Tratamentos de curta 
Quadro 1. Semelhanças metodológicas e conceituais entre o modelo da Reforma Psiquiátrica e o Movimento de Luta Antimanicomial com o das Comunidades Terapêuticas.

\begin{tabular}{|c|c|c|}
\hline $\begin{array}{l}\text { Conceitos } \\
\text { básicos }\end{array}$ & $\begin{array}{l}\text { Reforma Psiquiátrica e } \\
\text { Movimento de Luta } \\
\text { Antimanicomial }\end{array}$ & $\begin{array}{l}\text { Comunidade } \\
\text { Terapêutica }\end{array}$ \\
\hline Rede de serviços & $\begin{array}{l}\text { CAPS, residências terapêuticas, } \\
\text { hospital-dia, NASF, consultórios de } \\
\text { rua, etc. }\end{array}$ & $\begin{array}{l}\text { Atividades extramuros com foco na } \\
\text { ressocialização, grupos de apoio, hospital-dia } \\
\text { (modelo ambulatorial). }\end{array}$ \\
\hline Desinstitucionalização & $\begin{array}{l}\text { Eliminar as consequências da vida } \\
\text { institucional, como: violência, } \\
\text { miséria, isolamento, falta de } \\
\text { dignidade, injustiça e ampliação da } \\
\text { enfermidade institucional }{ }^{14} \text {. }\end{array}$ & $\begin{array}{l}\text { Postura anti-antiterapêutica }{ }^{25} \text {. Solucionar } \\
\text { agentes antiterapêuticos, patógenos, tais como } \\
\text { a privação sensorial e social, próprios das } \\
\text { instituições totais em geral, e do asilo clássico } \\
\text { em particular. }\end{array}$ \\
\hline $\begin{array}{l}\text { Superação do } \\
\text { paradigma da } \\
\quad \text { clínica }\end{array}$ & $\begin{array}{l}\text { "Tratar o doente, e não a doença"1, } \\
\text { num ambiente social, e não apenas } \\
\text { no consultório. }\end{array}$ & $\begin{array}{l}\text { "Não é a droga, mas a pessoa inteira, o } \\
\text { problema a ser tratado" } 10 \text {. O ambiente de } \\
\text { tratamento é a CT, um ambiente social. }\end{array}$ \\
\hline $\begin{array}{l}\text { Ampliação do } \\
\text { conceito de saúdel } \\
\text { Melhora na } \\
\text { qualidade de vida }\end{array}$ & $\begin{array}{l}\text { Melhora nas condições gerais de } \\
\text { vida, não somente na remoção dos } \\
\text { sintomas }{ }^{17} \text {. }\end{array}$ & $\begin{array}{l}\text { A recuperação envolve "re-habilitação", o que } \\
\text { seria restabelecer o funcionamento das } \\
\text { habilidades e valores saudáveis, assim como } \\
\text { resgatar a saúde física e emocional. Em outras } \\
\text { palavras, retomar um estilo de vida saudável }{ }^{21} \text {. }\end{array}$ \\
\hline Modelo psicossocial & $\begin{array}{l}\text { Os engajamentos subjetivo e } \\
\text { sociocultural são indissociáveis da } \\
\text { definição de saúde mental }{ }^{17} \text {. }\end{array}$ & $\begin{array}{l}\text { Considerar as relações interpessoais como o } \\
\text { principal agente de modificações de } \\
\text { comportamento no dependente }{ }^{10} \text {. }\end{array}$ \\
\hline $\begin{array}{l}\text { Horizontalização } \\
\text { das relações }\end{array}$ & $\begin{array}{l}\text { Mudança nas relações paciente- } \\
\text { paciente e paciente-equipe de } \\
\text { saúde, com maior participação de } \\
\text { todas as partes. }\end{array}$ & $\begin{array}{l}\text { A ideia primeva da CT seria o ambiente } \\
\text { democrático, de mobilidade social, no qual a } \\
\text { autoridade seria uma prerrogativa do grupo } \\
\text { como um todo, e não de um ou alguns } \\
\text { membros do mesmo }{ }^{5} \text {. }\end{array}$ \\
\hline $\begin{array}{l}\text { Controle social } \\
\text { compartido }\end{array}$ & $\begin{array}{l}\text { O paciente e os familiares teriam } \\
\text { prerrogativas semelhantes e } \\
\text { equivalentes às da equipe de saúde } \\
\text { para poder gerir cada fase do } \\
\text { tratamento. }\end{array}$ & $\begin{array}{l}\text { Todos os membros podem fazer-se } \\
\text { responsáveis pelo grupo e pela instituição, } \\
\text { independentemente das suas características } \\
\text { pessoais }^{5} \text {. }\end{array}$ \\
\hline
\end{tabular}

duração existem nas bases conceituais das CT, embora isto ainda não tenha sido convertido, de fato, em metodologia aplicada.

A questão agora seria: por que o trabalho das CT é considerado tão geralmente como absolutamente contraditório ao movimento da Reforma Psiquiátrica e ao Movimento de Luta Antimanicomial, se de acordo com os dados obtidos as suas bases conceituais e metodológicas são tão semelhantes?

A próxima seção dará conta de responder esta pergunta.

\section{A contramão do movimento}

Atualmente, segundo consta no site da FEBRACT $^{22}$, existem no Brasil 132 CT filiadas à mesma, e sabe-se que a quantidade de CT não filiadas excede, e muito, este número. Um exemplo disto é a pesquisa realizada por Laura Paes Machado $^{31}$, segundo a qual somente no Estado da Bahia teriam sido registradas 80 CT atuantes, enquanto que no registro da FEBRACT ${ }^{22}$ constam apenas três.

Segundo divulgado pelo SENAD ${ }^{32,33}$, existiriam entre 2500 a 3000 CT no Brasil, que atenderiam aproximadamente 60.000 dependentes químicos 
Quadro 1. continuação

\begin{tabular}{|c|c|c|}
\hline $\begin{array}{l}\text { Conceitos } \\
\text { básicos }\end{array}$ & $\begin{array}{l}\text { Reforma Psiquiátrica e } \\
\text { Movimento de Luta } \\
\text { Antimanicomial }\end{array}$ & $\begin{array}{l}\text { Comunidade } \\
\text { Terapêutica }\end{array}$ \\
\hline $\begin{array}{c}\text { Reapropriação da } \\
\text { identidade }\end{array}$ & $\begin{array}{l}\text { O que está em jogo é a } \\
\text { reapropriação do sujeito; do sentido } \\
\text { e da motivação humana; } \\
\text { reapropriação da capacidade de } \\
\text { forjar sua própria identidade }{ }^{6} \text {. }\end{array}$ & $\begin{array}{l}\text { O que deve ser tratado é a pessoa como ser } \\
\text { social e psicológico, ou seja, deve ser tratado o } \\
\text { modo como o dependente se comporta, } \\
\text { pensa, sente, administra suas emoções e } \\
\text { frustrações, suas culpas e tristezas, a sua } \\
\text { comunicação com o mundo externo e o } \\
\text { interno }^{10} \text {. }\end{array}$ \\
\hline Singularizaçãao & $\begin{array}{l}\text { Tratar o doente mental de acordo } \\
\text { com as suas características e } \\
\text { necessidades pessoais, fugindo da } \\
\text { lógica asilar capitalista de } \\
\text { massificação }{ }^{1} \text {. }\end{array}$ & $\begin{array}{l}\text { "É ao se esforçar para satisfazer as expectativas } \\
\text { de participação da comunidade que os } \\
\text { residentes perseguem suas metas individuais } \\
\text { de socialização e crescimento psicológico"10. }\end{array}$ \\
\hline Ressocialização & $\begin{array}{l}\text { Retorno do doente mental à } \\
\text { sociedade e à família, de acordo } \\
\text { com as reais possibilidades de cada } \\
\text { caso, buscando desenvolver diversos } \\
\text { dispositivos externos que se } \\
\text { adaptem a cada necessidade. }\end{array}$ & $\begin{array}{l}\text { Um dos principais avanços das CT } \\
\text { contemporâneas, para De Leon }{ }^{10} \text {, é “a } \\
\text { passagem [...] de uma comunidade alternativa } \\
\text { para dependentes químicos excluídos que } \\
\text { presumivelmente não tinham condições de } \\
\text { viver em sociedade a uma instituição de } \\
\text { serviços de atenção [...] que prepara os } \\
\text { indivíduos para a reintegração à sociedade } \\
\text { mais ampla". }\end{array}$ \\
\hline $\begin{array}{l}\text { Participação dos } \\
\quad \text { familiares }\end{array}$ & $\begin{array}{l}\text { Participação ativa na fundação do } \\
\text { movimento, assim como na gestão } \\
\text { das políticas públicas. }\end{array}$ & $\begin{array}{l}\text { Participação fundamental da família no } \\
\text { tratamento e na gestão do mesmo através de } \\
\text { acompanhamento individual ou de } \\
\text { participação em diversos Grupos de Apoio. }\end{array}$ \\
\hline
\end{tabular}

Quadro 2. Diferenças metodológicas e conceituais entre o modelo da Reforma Psiquiátrica e o Movimento de Luta Antimanicomial com o das Comunidades Terapêuticas.

\begin{tabular}{|c|l|l|}
\hline $\begin{array}{c}\text { Conceitos } \\
\text { básicos }\end{array}$ & \multicolumn{1}{|c|}{$\begin{array}{c}\text { Reforma Psiquiátrica e } \\
\text { Movimento de Luta } \\
\text { Antimanicomial }\end{array}$} & \multicolumn{1}{c|}{$\begin{array}{c}\text { Comunidade } \\
\text { Terapêutica }\end{array}$} \\
\hline Desospitalização & $\begin{array}{l}\text { Atendimento ao doente fora do } \\
\text { ambiente hospitalar, através dos } \\
\text { dispositivos da rede de serviços. }\end{array}$ & $\begin{array}{l}\text { Regime residencial, embora existam modelos } \\
\text { de CT ambulatorial. }\end{array}$ \\
\hline $\begin{array}{c}\text { Tratamentos de } \\
\text { curta duração }\end{array}$ & $\begin{array}{l}\text { Nos casos de internação, tempo } \\
\text { máximo de 90 dias. }\end{array}$ & $\begin{array}{l}\text { Tratamentos a partir de 6 meses de duração, } \\
\text { embora existam projetos de diminuição do } \\
\text { tempo mínimo de tratamento. }\end{array}$ \\
\hline
\end{tabular}

anualmente. Segundo a mesma pesquisa, mais de $55 \%$ das ONG que oferecem tratamento para a dependência do álcool e outras drogas no Brasil seriam CT, embora Hartmann ${ }^{32}$ afirme que, segundo pesquisa da Universidade de Brasília (UnB) juntamente com o Instituto de Pesquisa Econô- mica Aplicada (IPEA), mais de $80 \%$ dos tratamentos no Brasil são realizados dentro de CT.

Isto se configura um problema, já que grande parte destas CT não consta nos registros de nenhuma instituição regulamentadora, podendo ser esta tanto a própria FEBRACT, os respec- 
tivos Conselhos Municipais Antidrogas (COMAD), de Saúde (CMS), de Assistência Social (CMAS), dos Direitos da Criança e do Adolescente (CMDCA), a Agência Nacional de Vigilância Sanitária (Anvisa), ou qualquer outro órgão competente.

Este mesmo problema foi constatado pelo Relatório da 4a Inspeção Nacional de Direitos Humanos $^{15}$, referente aos locais de internação para usuários de drogas, elaborado pelo Conselho Federal de Psicologia, realizado em 24 Estados mais o DF, num total de 68 instituições, nas quais foi encontrada uma infinidade de irregularidades e abusos, como, por exemplo:

a) agressões físicas e morais;

b) constrangimento aos familiares nas visitas;

c) utilização de contenção química contra a vontade do indivíduo, sem o consentimento da família, e sem a presença de profissionais responsáveis;

d) cárcere privado;

e) desrespeito à orientação sexual;

f) imposição de credo religioso;

g) negligência de cuidados com a saúde;

h) condições indignas de alimentação, habitação e saneamento básico.

Muitos outros exemplos poderiam ser citados para ilustrar o grau de desrespeito para com o ser humano que demonstram muitas destas instituições, que erroneamente se autodenominam CT, mas com certeza estes já retratam uma realidade alarmante, muitas vezes desconhecida para aqueles que procuram pela primeira vez um serviço desta espécie.

Além de transgredir os princípios básicos dos Direitos Humanos, também transgridem a regulamentação oficial do Estado, que na Lei no 10.216, de 6 de Abril de $2001^{13,19}$, dispõe sobre a proteção e os direitos das pessoas portadoras de transtornos mentais, direcionando o modelo de assistência em saúde mental.

No Artigo $2^{\circ}$, inciso II, define-se que o indivíduo em tratamento deve ser tratado com humanidade e respeito, no interesse exclusivo de beneficiar sua saúde, visando alcançar sua recuperação pela inserção na família, no trabalho e na comunidade.

No inciso III do mesmo Artigo, a lei garante que o indivíduo em tratamento deve ser protegido contra qualquer forma de abuso e exploração.

$\mathrm{Na}$ regulamentação da Anvisa ${ }^{20}$, no Artigo 20 , consta que durante a permanência no tratamento a instituição deve garantir: a) o cuidado com o bem estar físico e psíquico da pessoa, proporcionando um ambiente livre de SPA e violência;

b) a observância do direito à cidadania do residente;

c) alimentação nutritiva, cuidados de higiene e alojamento adequados;

d) a proibição de castigos físicos, psíquicos ou morais;

e) a manutenção de tratamento de saúde do residente.

Como se pode conferir através destes dados, é evidente que grande parte das supostas CT em funcionamento no Brasil não atendem os requisitos mínimos de funcionamento, e é por este motivo que não devem ser denominadas sob o nome de CT. Como foi visto nas seções anteriores, o histórico e a essência do trabalho numa legítima CT divergem diametralmente daquilo que foi encontrado pelo CFP no levantamento citado, motivo pelo qual fica evidente que estas inconsistências não são produto das bases conceituais e metodológicas do movimento das CT, mas sim de uma prática indiscriminada e irresponsável daqueles que dirigem estes locais.

Cabe ressaltar, finalmente, que das 68 instituições investigadas pelo CFP, apenas quatro fazem parte da relação das CT filiadas fornecida pela FEBRACT, o que evidencia, mais uma vez, a necessidade de regulamentação e fiscalização que esta abordagem de trabalho exige, a fim de que seja realizado com seriedade e eficácia.

\section{Conclusões}

A trajetória da Reforma Psiquiátrica e do Movimento de Luta Antimanicomial no Brasil marca o início de um profundo processo de mudança no que diz respeito ao atendimento em Saúde Mental, visando tratamentos mais humanizados, que considerem a individualidade e a cidadania do portador de transtornos mentais de qualquer espécie.

Neste intuito muitos hospitais psiquiátricos foram fechados e, concomitantemente, foram abertas inúmeras vagas para atendimento nos setores da atenção primária, buscando modelos alternativos de atendimento, preferentemente fora de o ambiente hospitalar, altamente iatrogênico na maior parte dos casos.

Assim, foram criadas estratégias como os CAPS, NASF, residências terapêuticas, hospitais- 
dia, consultórios de rua e outros dispositivos que garantam a integralidade do atendimento, sem o ônus da hospitalização.

Por outro lado, o problema da dependência do álcool e outras drogas tem se alastrado de forma alarmante nas últimas décadas, o que tem provocado, em função da ausência de políticas públicas, a proliferação de uma série de locais de internação para este público, dentre estes as denominadas CT.

Embora em sua origem histórica, conceitual e metodológica, o movimento das CT tenha muitas mais semelhanças do que diferenças com o proposto pela Reforma Psiquiátrica e o Movimento de Luta Antimanicomial, na prática, pelo menos no Brasil, a realidade é diferente, como confirmado por diversas investigações realizadas na atualidade.

De fato, uma boa parte das CT no Brasil possui práticas tão desumanas e iatrogênicas quanto às das antigas instituições asilares manicomiais, sem garantir minimamente a preservação dos direitos humanos mais básicos.
Por outro lado também se percebeu que uma grande maioria destas supostas CT não recebe nenhuma forma de fiscalização, não se encontrando cadastrada em nenhum serviço de referência que regulamente sua prática, o que facilita ainda mais a proliferação e a prática indiscriminada.

Mas isto não significa, de forma alguma, que o conceito de CT se posiciona contra as bases do movimento reformista da saúde mental, já que, como foi demonstrado, as suas bases conceituais e metodológicas em muito se aproximam.

O que sim fica evidente é a necessidade de uma sistemática de fiscalização e regulamentação das CT, a fim de que somente permaneçam em atividade aquelas que, de fato, sigam o modelo proposto originalmente, nascido no mesmo berço da Reforma Psiquiátrica.

Desta forma, as CT poderão sim fazer parte das estratégias de atenção integral aos dependentes do álcool e outras drogas, consolidando-se como um excelente instrumento nos casos em que outras alternativas se mostrem ineficazes.

\section{Colaboradores}

NR Costa, SV Siqueira, D Uhr, PF Silva e AA Molinaro participaram igualmente de todas as etapas da elaboração do artigo. 


\section{Referências}

1. Tenorio F. A reforma psiquiátrica brasileira, da década de 1980 aos dias atuais: história e conceitos. Hist. Cienc. Saude-Manguinhos 2002; 9(1):25-59.

2. Sampaio JJC, Guimarães JMX, Carneiro C, Garcia Filho C. O trabalho em serviços de saúde mental no contexto da reforma psiquiátrica: um desafio técnico, político e ético. Cien Saude Colet 2011; 16(12):4685-4694.

3. Amarante P, organizador. Loucos pela vida: a trajetória da reforma psiquiátrica no Brasil. Rio de Janeiro: Fundação Osvaldo Cruz; 1995.

4. Jorge MAS. Engenho dentro de casa: sobre a construção de um serviço de atenção diária em saúde mental [dissertação]. Rio de Janeiro: Fundação Oswaldo Cruz; 1997.

5. Jones M. A Comunidade Terapêutica. Petrópolis: Ed. Vozes; 1972. (Coleção Psicanálise, V. 3).

6. Lüchmann LHH, Rodrigues J. O movimento antimanicomial no Brasil. Cien Saude Colet 2007; 12(2):399-407.

7. Pitta AMF. Um balanço da reforma psiquiátrica brasileira: instituições, atores e políticas. Cien Saude Colet 2011; 16(12):4579-4589.

8. Mari JJ. Um balanço da reforma psiquiátrica brasileira. Cien Saude Colet 2011; 16(12):4593-4596.

9. Costa NR, Siqueira SV, Uhr D, Silva PF, Molinaro AA. Reforma psiquiátrica, federalismo e descentralização da saúde pública no Brasil. Cien Saude Colet 2011; 16(12):4603-4614.

10. De Leon G. A Comunidade Terapêutica: teoria, modelo e método. 2a Edição. São Paulo: Edições Loyola; 2008.

11. Fracasso L. Comunidade Terapêutica: uma abordagem psicossocial. Campinas: Universidade Estadual de Campinas - Faculdade de Educação Física. [página na Internet]. 2008 [acessado 2011 out 04]. Disponível em: http://www.fef.unicamp.br/biblioteca/ Encontrointerdisciplinar/Texto\%202\%20Laura.pdf.

12. Goti ME. La comunidad terapéutica: un desafío a la droga. Buenos Aires: Nueva Visión; 1990.

13. Brasil. Ministério da Saúde (MS). A Política do Ministério da Saúde para a atenção integral a usuários de álcool e outras drogas. Brasília: MS; 2003.

14. Agência Nacional de Vigilância Sanitária. Resolução - RDC no 101, de 30 de maio de 2001. Dispõe sobre os requisitos de segurança sanitária para o funcionamento de instituições que prestem serviços de atenção a pessoas com transtornos decorrentes do uso, abuso ou dependência de substâncias psicoativas. Diário Oficial da União 2001; 31 maio.

15. Conselho Federal de Psicologia. Relatório da $4^{a}$ Inspeção Nacional de Direitos Humanos: locais de internação para usuários de drogas. 2a Edição. Brasília: Conselho Federal de Psicologia. [página na Internet]. 2011 [acessado 2012 fev 10]. Disponível em: http://www.pol.org.br/pol/export/sites/default/pol/ publicacoes/publicacoesDocumentos/2a_Edixo_ relatorio_inspecao_VERSxO_FINAL.pdf.

16. Vecchia MD, Martins STF. Desinstitucionalização dos cuidados a pessoas com transtornos mentais na atenção básica: aportes para a implementação de ações. Interface (Botucatu) 2009; 13(28):151-164.
17. Costa-Rosa A, Luizio CA, Yasui S. As Conferências Nacionais de Saúde Mental e as premissas do Modo Psicossocial. Saúde em Debate 2001; 25(58):12-25.

18. Saraceno B, Asioli F, Tognoni G. Manual de Saúde Mental: guia básico para atenção primária. São Paulo: Hucitec; 1994.

19. Brasil. Ministério da Saúde (MS). Abordagens Terapêuticas a Usuários de Cocaína/Crack no Sistema Unico de Saúde: Texto preliminar destinado à consulta pública. Brasília: MS; 2010.

20. Agência Nacional de Vigilância Sanitária (Anvisa). Resolução RDC no 29, de 30 de Junho de 2011. Dispõe sobre os requisitos de segurança sanitária para o funcionamento de instituições que prestem serviços de atenção a pessoas com transtornos decorrentes do uso, abuso ou dependência de substâncias psicoativas. Diário Oficial da União 2011; 1 jul.

21. National Institute of Drug Abuse (NIDA). La Comunidad Terapéutica. [página na Internet]. [acessado 2011 out 11] Disponível em: http://www.nida. nih.gov/ResearchReports/Terapeutica/Terapeutica. html.

22. Federação Brasileira de Comunidades Terapêuticas (FEBRACT). Comunidades Terapêuticas Filiadas - Titulares e Provisórias. [página na Internet] [acessado 2012 mar 11]. Disponível em: www.febract. org.br /filiadas.htm.

23. Federação Brasileira de Comunidades Terapêuticas (FEBRACT). [página na Internet] [acessado 2009 abr 5]. Disponível em: www.febract.org.br.

24. Goñi JJL. Evaluación de la eficácia de la Comunidad Terapéutica de Proyecto Hombre de Navarra [tese]. Pamplona: Universidad Pública de Navarra; 2005.

25. Rodrigué E. Biografía de una Comunidad Terapéutica. Buenos Aires: Editorial Universitaria de Buenos Aires; 1965.

26. Badaracco JEG. Comunidade Terapêutica Psicanalítica de Estrutura Multifamiliar. São Paulo: Casa do Psicólogo; 1994.

27. Araujo MR. Comunidades Terapêuticas: um ambiente tratamento comum, mas pouco estudado no Brasil. Hospital Israelita Albert Einstein. [página na Internet] 2003. [acessado 2011 out 10] Disponível em: http://apps.einstein.br/alcooledrogas/novosite/ atualizacoes/as_137.htm.

28. Aliane PP, Lourenço LM, Ronzani TM. Estudo comparativo das habilidades sociais de dependentes e não dependentes de álcool. Psicologia em estudo 2006; 11(1):83-88.

29. Sabino NM, Cazenave SOS. Comunidades terapêuticas como forma de tratamento para a dependência de substâncias psicoativas. Estudos de Psicologia (Campinas) 2005; 22(2):167-174.

30. Lourenço RA. A família do dependente químico. In: Monte Serrat S, organizador. Drogas e álcool: Prevenção e tratamento. Campinas: Komedi; 2012. p. 170-177.

31. Machado LP. Comunidades Terapêuticas: saber e poder na rede de atenção a usuários de substâncias psicoativas. [página na Internet] [acessado $2012 \mathrm{mar}$ 11] Disponível em: http://www.interativadesignba. com.br/III_SPSC/arquivos/sessao4/098.pdf. 
32. Hartmann R. Detalhamento do encontro dos representantes de Comunidades Terapêuticas do Brasil com a presidente Dilma Roussef. Brasília. [página na Internet] 2011. [acessado 2012 mar 12]. Disponível em:http://grupodeapoiogadefacruzazul.blogspot. com/2011/07/encontro-comunidades-terapeuticasdo.html.

33. Brasil. Mapeamento das instituições governamentais e não-governamentais de atenção às questões relacionadas ao consumo de álcool e outras drogas no Brasil - 2006/2007. Brasília. [página na Internet] 2007. [acessado 2012 mar 12]. Disponível em: http:// www.obid.senad.gov.br/portais/OBID/biblioteca/ documentos/Dados_Estatisticos/Instituicoes/ 327691.pdf.

Artigo apresentado em 23/01/2013

Aprovado em 03/03/2013

Versão final apresentada em 16/03/2013 